\title{
Does Inhibitory Control Training Improve Health Behaviour? A Meta-Analysis
}

\author{
Vanessa Allom $^{1,2^{*}}$, Barbara Mullan ${ }^{1,2}$, Martin Hagger ${ }^{1}$
}

${ }^{1}$ Health Psychology and Behavioural Medicine Research Group, School of Psychology and Speech Pathology, Curtin University, Australia

${ }^{2}$ School of Psychology, University of Sydney, Australia

*Corresponding author: Vanessa Allom, vanessa.allom@curtin.edu.au

Acknowledgements: This work was supported under the Australian Research Council's

Linkage Projects Scheme (project number LP110100220) in collaboration with WorkCover Authority NSW. 


\begin{abstract}
Objectives: Inhibitory control training has been hypothesised as a technique that will improve an individual's ability to overrule impulsive reactions in order to regulate behaviour consistent with long-term goals.

Methods: A meta-analysis of 19 studies of inhibitory control training and health behaviours was conducted to determine the effect of inhibitory control training on reducing harmful behaviours. Theoretically-driven moderation analyses were also conducted to determine whether extraneous variables account for heterogeneity in the effect; in order to facilitate the development of effective intervention strategies. Moderators included type of training task, behaviour targeted, measurement of behaviour, and training duration.

Results: A small-but homogenous effect of training on behaviour was found $\left(d^{+}=0.378, \mathrm{CI}_{95}=\right.$ $[0.258,0.498])$. Moderation analyses revealed that the training paradigm adopted, and measurement type influenced the size of the effect such that larger effects were found for studies that employed go/no-go training paradigms rather than stop-signal task paradigms, and objective outcome measures that were administered immediately yielded the largest and most consistent effects on behaviour.

Conclusions: Results suggest that go/no-go inhibitory control training paradigms can influence health behaviour, but perhaps only in the short-term. Future research is required to systematically examine the influence of training duration, and the longevity of the training effect. Determining these factors could provide the basis for cost-effective and efficacious health promoting interventions.
\end{abstract}

Keywords: Inhibitory control; training; health behaviour; meta-analysis; stop-signal; go/no-go 


\section{Does Inhibitory Control Training Improve Health Behaviour? A Meta-Analysis}

\section{Inhibitory control and health behaviour}

Inhibitory control refers to an individual's capacity to overrule impulsive reactions in order to regulate behaviour in line with long-term goals (Miyake et al., 2000; Nederkoorn, Houben, Hofmann, Roefs, \& Jansen, 2010). Generally, research indicates that the behaviour of individuals low in inhibitory control is dominated by impulsive precursors such as implicit preferences, rather than more reflective precursors such as intentions or goals (Hofmann et al., 2009). Research has suggested that this construct is particularly important for the regulation of health behaviours including dietary fat intake (Hall, 2012) and sleep hygiene (Todd \& Mullan, 2013), and addictive behaviours including alcohol consumption (Houben \& Wiers, 2009). Specifically, deficits in inhibitory control have been associated with poorer eating behaviour (Hall, 2012; Hofmann, Friese, \& Roefs, 2009), weight gain (Nederkoorn et al., 2010), and increased alcohol consumption (Houben \& Wiers, 2009; Murphy \& Garavan, 2011).

\section{Inhibitory control training}

Current research suggests that inhibitory control can be trained to improve the regulation of health behaviour. This typically involves regular practice on a cognitive task said to tax inhibitory control, such as the go/no-go task (GNG; Donders, 1969) or the stop-signal task (SST; Lappin \& Eriksen, 1966). Improvement in health behaviour is usually assessed using a between-participants design wherein participants who are randomly assigned to receive inhibitory control training are expected to demonstrate positive health-related outcomes compared to those assigned to an inert or alternative form of training (Houben \& Jansen, 2011; Jones \& Field, 2013; van Koningsbruggen, Veling, Stroebe, \& Aarts, 2013). Specifically, in GNG training paradigms, participants are required to respond as rapidly as possible to a neutral set of stimuli while withholding responses to a set of stimuli representing the target behaviour. Consistent pairings of the no-go response with target stimuli facilitates the retrieval of no-go- 
target stimuli associations and results in improved inhibition of responses to target stimuli (Spierer, Chavan, \& Manuel, 2013). For example, Houben, Nederkoorn, Wiers, and Jansen (2011) used a GNG with alcohol-related stimuli in an attempt to reduce alcohol consumption. Participants in the training condition reported less alcohol consumption after training compared to the control condition, suggesting that an association between alcohol stimuli and a no-go response had formed and that this transferred to reduced alcohol consumption (Houben et al., 2011).

In SST training paradigms, participants are instructed to categorise both target stimuli and neutral stimuli as rapidly as possible; however, on a proportion of trials the stop-signal is presented after target stimuli and participants are required to inhibit their responses. In this way, an association between target stimuli and the stop response is established. In the control condition, stop-signals are not consistently paired with a particular category of stimuli, or are not presented at all. Lawrence, Verbruggen, Morrison, Adams, and Chambers (2015) demonstrated that participants who received SST training in which stop-signals were paired with unhealthy foods consumed significantly less high-calorie food immediately after training, compared to those in the control condition (Study1). This suggests that establishing an association between unhealthy food and a stop response results in a reduction in consumption of unhealthy foods.

The studies described above appear to indicate that inhibitory control training is an effective technique to improve the regulation of health behaviour. However, there exists variability in the findings across the literature. For example, Houben and Jansen (2011) trained participants on a GNG with chocolate stimuli and failed to demonstrate differences in chocolate consumption between no-go and go conditions in an ostensible taste test. Additionally, while Houben, Havermans, Nederkoorn, and Jansen (2012) demonstrated significant differences in self-reported alcohol consumption between training and control conditions, both Bowley et al. (2013) and Jones and Field (2013) failed to replicate this effect. 
Based on these inconsistencies, there is a need to determine the precise size and variability of the inhibitory control training effect.

While numerous inhibitory control training studies have been carried out with varying success regarding their effect on health behaviour, few studies have attempted to ascertain the mechanism responsible for such differences. Preliminary evidence suggests that GNG training improves health behaviour by changing impulsive tendencies, or via 'bottom-up inhibition' (Verbruggen \& Logan, 2008). For example, Houben et al. (2012) employed an implicit association task (IAT; Greenwald, McGhee, \& Schwartz, 1998), and another measure of inhibitory control (the SST), and demonstrated that GNG training reduced alcohol consumption by devaluation of the alcohol-related stimuli rather than by improvement on the SST, suggesting that GNG training results in a decrease in the influence of impulsive processes. This is in contrast to mechanistic explanations regarding the effects of SST training, where it has been suggested that SST training improves health behaviour by strengthening 'top-down' inhibitory control (Houben \& Jansen, 2011). Allom and Mullan (2015) demonstrated that SST training improved Stoop performance, another measure of inhibitory control; however, this was not related to change in health behaviour. This suggests that GNG training may be more effective at changing health behaviour than SST training, due to different underlying mechanisms.

In summary, inhibitory control training does appear to influence health behaviour; however, the precise size and variability of this effect is not yet known. Examining the effect of training across the available literature, and determining whether any variance in the effect size is due to between study differences such as task paradigm, will determine the efficacy of training interventions and elucidate the parameters for effective implementation of these interventions. 


\section{Potential moderators of training effect}

Evidence points to a number of theoretically-plausible moderators that may influence the effect of inhibitory control training on health behaviour. In the next section, the potential moderators are outlined and how they might affect the relationship between inhibitory control training and health behaviour is explored.

Training paradigm. As described above, the mechanisms by which the two typically adopted paradigms influence health behaviour may differ (Allom \& Mullan, 2015; Houben et al., 2012). This is likely due to differences in the features of the tasks. For example, in the GNG, the go response is consistently inhibited for all items in a certain category, whereas in the SST the go response is inhibited only for a certain proportion. Therefore examining whether the effectiveness of training differs according to training paradigm will not only assist with task selection for interventions but also help to elucidate the mechanism by which these tasks influence behaviour.

Type of stimuli. Both the GNG and the SST can be tailored to train inhibitory control in response to a group of stimuli associated with a particular target behaviour, such as alcohol consumption. In contrast, several studies have also utilised an inhibitory control task with neutral stimuli (Guerrieri, Nederkoorn, \& Jansen, 2012; Guerrieri, Nederkoorn, Schrooten, Martijn, \& Jansen, 2009; Lawrence et al., 2015), hypothesising that training of a general inhibitory control mechanism is sufficient to improve health-related outcomes in a specific domain. While it is likely that the effect of training is larger when behaviour-relevant stimuli are used in training tasks because a specific association between the no-go/stop response and the target stimuli is being established, testing this in a moderator analysis will determine the precise difference in effect size between the two forms of training.

Training duration. Inhibitory control training is typically conducted in a single session (Bowley et al., 2013; Houben et al., 2012; Jones \& Field, 2012; Veling, Aarts, \& Papies, 2011). However, the number of trials that a training session involves differs across 
studies. Currently there is no direct evidence that longer training sessions are more beneficial. In addition, there may be a threshold for training effects beyond which the benefits of training plateau and no new gains are achieved regardless of further training. In order to establish more parsimonious interventions, it is therefore important to examine how training duration (number of task trials) influences health behaviour.

Type of health behaviour. It is possible that the effectiveness of inhibitory control training differs according to the characteristics of the target health behaviour. For example, research has demonstrated a stronger relationship between inhibitory control and health risk behaviours such as snack consumption, compared to health enhancing behaviours such as fruit and vegetable consumption (Allom \& Mullan, 2014; Hall, 2012). Further, McEachan, Lawton, and Conner (2010) offered a framework for classifying and predicting health behaviours based on the unique characteristics of the behaviour, suggesting that not all health behaviours have the same determinants. Inhibitory control training may, therefore, produce different results simply based on the type of health behaviour that is targeted.

Behaviour measurement. A methodological concern that may account for variation in effect sizes across studies is the way in which behaviour is measured. While self-report measures may be subject to reporting bias, they may also offer a more externally valid assessment of behaviour than laboratory-based measures such as ostensible taste tests (Smyth et al., 2001), which have been used to measure alcohol and food consumption post-training (Bowley et al., 2013; Houben, 2011; Jones \& Field, 2013; Nagy, 2012).

Length of follow-up. While previous research has demonstrated differences in health behaviour when behavioural measures are administered immediately post-training (Houben, 2011), studies that have measured behaviour up to a week post-training have produced both significant differences in health behaviour outcomes (Houben et al., 2012), and non-significant results (Bowley et al., 2013; Jones \& Field, 2013). Given the lack of conclusive evidence regarding the longevity of the inhibitory control training effect on health behaviour, it is 
important to examine the extent to which the effect of training diminishes over time. Therefore, length of follow-up will be used to determine the longevity of the training effect.

\section{Present analysis}

Inhibitory control training appears to show promise as an intervention to improve the regulation of health behaviours; however, there is substantial observed variation in the strength of the effects across the literature (e.g., Bowley et al., 2013; Houben et al., 2012). This article makes a unique contribution to knowledge of behaviour change and inhibitory control by attempting to determine the size and variability of the effect of inhibitory control training on health behaviour. We acknowledge that inhibitory control is a multifaceted construct comprising several similar yet distinct inhibitory processes (Friedman \& Miyake, 2004), including response inhibition, cognitive inhibition, and interference control (Gray \& McNaughton, 2000; Nigg, 2000). The current review will focus exclusively on response inhibition - the suppression of actions that interfere with goal-directed behaviour - primarily because the tasks used to assess and train this inhibitory process (i.e., GNG and SST) directly and uniquely demand response inhibition whereas other inhibitory control tasks (e.g., the Flanker and the Stroop tasks) demand other elements of inhibition (Spierer et al., 2013). In addition, research with the aim of training self-control by changing behaviour will not be considered for similar reasons (e.g., Muraven, 2010; Oaten \& Cheng, 2006). Specifically, selfcontrol training involves modifying an element of behaviour typically for a two-week period, such as maintaining the correct posture. While this action would demand inhibitory control, it is unclear whether other processes are also influencing behaviour change.

A secondary aim is to determine whether potential moderators account for unique variance in the inhibitory training effect across studies. Determining whether extraneous variables moderate the effect may assist in the development of effective inhibitory control strategies to promote better regulation of health behaviours. 


\section{Method}

\section{Search strategy}

A systematic literature search was conducted of electronic databases including PsycINFO, Medline, Scopus, and ProQuest Dissertations. The search period was from 1990 up to and including January 2014. The search was updated in February 2015. This period corresponds to the development of the SST (Schachar \& Logan, 1990) and the GNG with cues (Marczinski \& Fillmore, 2003). The search terms used were: (go no go OR go nogo OR go no-go OR stop signal OR stop-signal OR response inhibition OR inhibitory control) AND (training OR intervention OR modif*). Searches were limited to human studies, English language publications, and adult populations. In addition, reference sections of retrieved articles were examined, as were the reference sections of key narrative review articles of response inhibition studies (Jones, Christiansen, Nederkoorn, Houben, \& Field, 2013; Spierer et al., 2013). Finally, key authors and researchers in the field were contacted for any additional unpublished data sets; however, this did not yield any further data.

\section{Inclusion and exclusion criteria}

Studies were included in the analysis if they met the following inclusion criteria: (1) inclusion of at least one session of SST or GNG training; (2) adoption of an experimental or randomised controlled design; (3) inclusion of a health behaviour outcome measure; and (4) contained sufficient statistical information to compute an effect size such as cell means and standard deviations, or $F$ ratios, or $t$-statistics. When the relevant statistics were not reported for otherwise eligible studies, authors were contacted to obtain the necessary information.

There were no restrictions on the nature of behaviour measurement (i.e., self-report or objective behaviour), or publication status (i.e., available unpublished data were included). Studies that included two interacting intervention techniques in a single condition using a nonfactorial design (e.g., GNG training and diary keeping) were also excluded. Studies that 
included measures of behavioural outcomes that used the same task or stimuli to assess transfer to behaviour, were also excluded as this might have confounded findings.

\section{Information extracted and meta-analytic strategy}

Means and standard deviations of performance on behavioural outcomes were extracted for each condition; when unavailable from the manuscript, authors were contacted to provide this information. Where possible, pre and post measures of behavioural outcomes were extracted and effect sizes, controlling for pre-scores, were calculated. All information was entered into Excel spread sheets by two of the authors.

Comprehensive Meta-Analysis v. 2.0 (Borenstein, Hedges, Higgins, \& Rothstein, 2005) was used for calculating effect sizes and conducting all analyses including analyses to examine small-study bias, heterogeneity, and moderation. The effect size metric employed in the current analysis was Cohen's $d$ (Cohen, 1988), which represents the standardised mean difference score for experimental and control conditions. Although a systematic literature search was conducted, a random effects model was used in order to control for the possibility that relevant articles were missed (Borenstein, Hedges, \& Rothstein, 2007). A random effects model is also recommended when samples across studies are heterogeneous (DerSimonian \& Laird, 1986), as was the case in the included studies.

For each effect size a 95\% confidence interval $\left(\mathrm{CI}_{95}\right)$ was calculated, and Cochrane's $Q$ and $I^{2}$ statistics were used to explore heterogeneity (Huedo-Medina, Sánchez-Meca, MarinMartinez, \& Botella, 2006). If $Q$ is statistically significant, heterogeneity is present. $I^{2}$ expressed heterogeneity as a percentage of the total variation across the included studies. $I^{2}$ values up to $25 \%$ indicated low heterogeneity, up to $50 \%$ indicated moderate heterogeneity, and up to $75 \%$ or higher indicated high heterogeneity (Higgins, Thompson, Deeks, \& Altman, 2003). A moderator analysis was conducted in a mixed-effects model (Hunter \& Schmidt, 2000). 


\section{Moderator coding}

Moderator coding was initially conducted by the first two authors. The agreement between the authors was high $(\kappa=.78, p<.001)$. Discrepancies were discussed with all three authors, and a consensus decision was made to resolve the ambiguity.

Training paradigm. Studies were coded according to their use of the GNG or SST as the training treatment. Tasks requiring participants to withhold a response to all members of a category was categorised as having used a GNG. Tasks requiring participants to withhold responding to a proportion of stimuli within a category were categorised as having used an SST. Note that these criteria were followed, rather than terms used by authors such that there may be some discrepancies between our coding and authors' labels (e.g., Veling, Aarts, \& Papies, 2011; Veling, Aarts, \& Stroebe, 2013b)

Type of stimuli. Studies were also coded according to their use of behaviour-specific or neutral stimuli in the training task. If studies included both types of tasks as separate conditions, and compared the performance of these conditions to the same control condition, only the behaviour-specific and control comparison was included in order to maintain independence of effect sizes. If studies included a condition in which inhibition towards both behaviour-specific and neutral stimuli was trained concurrently, comparisons between this condition and others were not included due to potential confounds in the concurrent training condition. If the training condition was compared to a non-standard control condition, these comparisons were excluded due to a lack of consistency across control conditions.

Type of task. There was overlap between type of training task and the behavioural specificity whereby no studies included a neutral GNG. Therefore, a moderator variable was created that incorporated both of these elements: GNG, SST-specific, or SST-neutral training.

Training duration. In order to assess whether duration of training influenced behavioural outcomes, a meta-regression was conducted with number of trials entered as a continuous predictor of the inhibitory control training effect size. 
Type of health behaviour. Initially, an analysis in which behaviours were categorised into health risk or health enhancing behaviours was planned; however, no included studies attempted to improve a health enhancing behaviour. Consequently, behaviours were instead categorised according to whether they targeted eating behaviour, or alcohol consumption.

Objective versus subjective. Studies were coded according to the type of behaviour measure: objective measures included laboratory-based taste tests or choice tasks; subjective measures included self-reported behaviour.

Length of follow-up. A moderator variable was created to assess the time at which differences in behaviour were assessed: immediate-assessment (immediately after training) vs. post-assessment (all other time frames).

Measurement of behaviour. There was overlap between how and when behaviour was assessed. Immediately administered measures were laboratory-based, whereas post-assessment measures tended to be self-report. Therefore, these two moderators were combined into a single moderator: immediate-objective, post-objective, or post-subjective.

\section{Risk of bias}

An effort was made to include unpublished studies and datasets, as including only published studies risks inflation of effects due to significant results potentially being more likely to be published (Hopewell, McDonald, Clarke, \& Egger, 2007). The fail-safe N (Rosenberg, 2005), was also computed to estimate how many potential effects may be required to reduce the overall averaged corrected effect size to a trivial size. However, the fail-safe $\mathrm{N}$ does not control for 'small study' effects, which may reflect a tendency for low-powered small studies to be included in published data sets (Hopewell et al., 2007). Such effects may be indicative of publication bias (Sterne, Egger, \& Smith, 2001). This can be detected by examining the plot of the effect size against study precision, that is, the reciprocal of the standard error. The distribution should reflect a 'funnel' shape, such that larger studies appear close to the true effect size and smaller, and therefore more imprecise, studies fall further away and should be 
evenly distributed. Bias is present if values are not evenly distributed within the funnel or fall outside the funnel shape. Funnels for the effect sizes in the current study and moderator subgroups were examined. Duval and Tweedie's (2000) Trim and Fill procedure was applied to control for 'small study' effects in which studies with disproportionately large effects with small sample sizes that are not evenly distributed are removed and 'filled' with hypothetical studies to revolve the uneven distribution. To the extent that the averaged corrected effect size remains unchanged after the trim and fill, we have evidence that the sample of studies is unaffected by the small-study bias identified by Egger, Smith, Schneider, and Minder (1997).

\section{Results}

After duplicates were removed, the search strategy identified 625 records that were title screened, resulting in 54 records that were screened at the abstract stage. After exclusions, 18 full text articles were screened. The search identified 23 effect sizes that were eligible for inclusion in the meta-analysis. However, data sets for two studies eligible for inclusion, but with insufficient data to compute effect size, could not be obtained through direct contact with the authors (Guerrieri et al., 2012; Guerrieri et al., 2009) and were therefore excluded. In addition, effect sizes for the influence of training on one outcome measure could not be obtained from one study (Nagy, 2012). One study measured behaviour using a task that included the same stimuli that participants were trained on, and was therefore not included due to possible issues with the generalisability of the findings (Veling, Aarts, \& Stroebe, 2013a). Finally, Todd and Mullan (2013) used both GNG training and diary keeping concurrently to influence behaviour. As the effect of GNG training alone could not be determined from this data, this study was excluded. Therefore, 14 articles with 19 independent tests of the training effect were included in the meta-analysis. All included studies were peer reviewed except Nagy (2012), which was a masters dissertation. Figure 1 shows the study selection process. 


\section{Characteristics of included studies}

The mean sample size within the datasets was 73 One study included a neutral inhibitory control training task (Lawrence et al., 2015: Study 3); a further two included both a behaviourspecific condition and a neutral task training condition (Jones \& Field, 2013; Nagy, 2012). In order to maintain independence of effect sizes, only the effect size for the behaviour-specific and control comparison was extracted and entered into the analysis. Four studies included a condition in which participants were trained on both behaviour-specific and neutral stimuli concurrently (Allom \& Mullan, 2015; Houben, 2011; Houben \& Jansen, 2011). In addition, one study included a previously-established intervention strategy as a secondary control condition (Bowley et al., 2013), namely, the Brief Alcohol Intervention (Hallett, Maycock, Kypri, Howat, \& McManus, 2009). Comparisons between inhibitory control training and these control conditions were not included due to the small number of studies utilising non-standard control conditions.

Two different types of behaviours were reported: alcohol consumption $(\mathrm{k}=5)$, and eating behaviour outcomes $(\mathrm{k}=14)$. The majority of studies used a single behaviour measure to assess the effect of training. The most frequently used objective measure was an ostensible taste test administered immediately after the training session, while the most frequent subjective measure was a self-report questionnaire. In one study, participants were given a small bag of palatable food to take home and return the next day after consuming as much or as little of the food as they liked (Veling et al., 2011). As this measure was subject to confound; for example, other individuals may have consumed the contents of the bag, this was considered a subjective measure. While some studies used both objective and subjective measures of health behaviour in the same study, this was confined to the studies examining the effect of training on alcohol consumption (Bowley et al., 2013; Houben et al., 2011; Jones \& Field, 2013; Nagy, 2012), where both an ostensible taste test and the Timeline Follow-back questionnaire (Sobell \& Sobell, 1992) were used to assess differences in alcohol consumption 
between trained and non-trained conditions. For these studies, the mean of the effect size across measures was taken. Length of follow-up ranged from 1 day to 1 week. Finally, in studies that used a pre-post design to assess change in behaviour (Allom \& Mullan, 2015; Houben et al., 2012; Veling, van Koningsbruggen, Aarts, \& Stroebe, 2014), the effect size was calculated after taking into account baseline behaviour. See Table 1 of Supplementary material for detailed characteristics of included studies, and moderator coding.

\section{Overall training effect}

The averaged corrected standardised mean difference for response inhibition training on health behaviour was $d^{+}=0.378, \mathrm{CI}_{95}=[0.258,0.498], p<.001$. This represents an effect that falls between the small (0.20) and medium (0.50) effect size guidelines proposed by Cohen (1988). See Figure 2 for a forest plot of the included effect sizes. Tests for heterogeneity indicated that there was no substantial heterogeneity in the effect size across studies, $Q(18)=16.501, p=$ $.558 ; I^{2}=00.00 \%$, indicating that the true effect size was likely to fall between the confidence interval indicated. In addition, the effect size could also be considered non-trivial given that the confidence interval did not include zero. The fail safe sample-size $\left(N_{\mathrm{FS}}=176\right)$ exceeded the suggested cut off value, indicating that it was highly unlikely that sufficient studies with null effects exist which, if included, could reduce the size of the effect. However, inspection of funnel plot and application of Duval and Tweedie's (2000) Trim and Fill method suggested that three studies were missing on the left side of the mean effect size. This indicated that the included small-studies, which fell to the right of the mean, may have inflated the effect size. Using the Trim and Fill method to adjust for small-study bias, the imputed point estimate was $d^{+}=0.328, \mathrm{CI}_{95}=[0.214,0.441]$, as this effect remained significant, the true effect size is not substantially influenced by small study bias..

Insert Figure 2 near here 


\section{Moderator analyses}

The overall analysis revealed a homogenous effect of inhibitory control training on health behaviour, indicating low variability between studies, and a lack of extraneous variables influencing the effect. However, moderator analyses were conducted as planned given the numerous theoretical and conceptual reasons outlined in the previous sections. We deemed it important to explore these moderators on the basis that any differences detected would be useful for researchers intending to use inhibitory control training in future behaviour change interventions.

Training paradigm. Studies that utilised a GNG training paradigm yielded a medium effect size, $d^{+}=0.503, \mathrm{CI}_{95}=[0.348,0.658], p<.001$, whereas studies utilising the SST yielded small, marginally significant effect sizes, $d^{+}=0.190, \mathrm{CI}_{95}=[0.000,0.380], p=.050$. Both groups of effect sizes were homogenous. See Table 1 for all moderator statistics.

Type of stimuli. The effect of training on health outcomes when the task was tailored to the specific behaviour resulted in an effect of $d^{+}=0.419, \mathrm{CI}_{95}=[0.293,0.546], p<.001$; the effect of training using a neutral response-inhibition task was not statistically significant, $d=-$ 0.027, $\mathrm{CI}_{95}=[-0.421,0.367], p=.894$. Both effects were homogenous.

Type of task. Examining the effect of training according to both the training paradigm, and whether the task was tailored to a specific behaviour or used neutral stimuli, revealed that the tailored version of the GNG yielded a medium effect size, $d^{+}=0.503, \mathrm{CI}_{95}=[0.348,0.658]$, $p<.001$, while the tailored version of the SST yielded a small effect size, $d^{+}=0.256, \mathrm{CI}_{95}=$ $[0.039,0.473], p=.021$. However, the effect of neutral SST training on health behaviour was not statistically significant, $d^{+}=-0.027, \mathrm{CI}_{95}=[-0.421,0.367], p=.849$. These effect sizes were homogenous.

Training duration (number of trials). The slope examining number of trials as a predictor of the size of the training effect was not statistically significant. 
Type of health behaviour. Training produced significant homogenous effects on alcohol consumption, $d^{+}=0.433, \mathrm{CI}_{95}=[0.195,0.671], p<.001$, and eating behaviour, $d^{+}=$ $0.366, \mathrm{CI}_{95}=[0.214,0.518], p<.001$.

Objective versus subjective. Training outcomes measured objectively produced homogenous effects on behaviour, $d^{+}=0.430, \mathrm{CI}_{95}=[0.263,0.597], p=.001$, whereas subjective measures produced small effect sizes $d^{+}=0.271, \mathrm{CI}_{95}=[0.036,0.506], p=.024$.

Length of follow-up. Behaviour measured immediately after training resulted in a homogenous effect, $d^{+}=0.433, \mathrm{CI}_{95}=[0.261,0.605], p<.001$. Behaviour measured at a later time point produced a small, homogenous effect $d^{+}=0.295, \mathrm{CI}_{95}=[0.085,0.506], p=.006$

Measurement of behaviour. Objective measures administered immediately after training produced an effect size of $d^{+}=0.433, \mathrm{CI}_{95}=[0.261,0.605], p<.001$, and was homogenous. Conversely, objective measures administered at a later point in time were not significant, $d^{+}=0.404, \mathrm{CI}_{95}=[-0.294,1.102], p=.257$, and were moderately heterogeneous, $Q(1)=3.050, p=.081, I^{2}=67.20 \%$. Subjective measures administered at a later point in time yielded a homogenous, small effect size $d^{+}=0.271, \mathrm{CI}_{95}=[0.036,0.506], p=.024$.

Insert Table 1 near here

\section{Discussion}

This is the first comprehensive meta-analysis of the effect of inhibitory control training on health behaviour. The aim was to address the observed variation in findings within the inhibitory control training literature by conducting a quantitative cumulative analysis of studies examining the effect of inhibitory control training on health behaviour. The meta-analysis of the overall training effect produced a small but homogenous effect size, which was considered non-trivial. This suggests that inhibitory control training may be a useful intervention technique for reducing health risk behaviours. However, given that the size of the effect was small, inhibitory control training may be more useful as an adjunct to other effective intervention techniques. For example, Veling et al. (2014) demonstrated that GNG training and 
implementation intentions together had a greater effect on weight loss than the two techniques separately. Regardless of whether inhibitory control training is used as an adjunct or standalone technique, it is useful to know the optimal paradigm to implement. With this in mind, conceptually driven moderation analyses were conducted, revealing differences in the size of the training effect according to type of task, and measurement of behaviour. Training effects did not differ according to the length of training, nor the type of behaviour targeted. Each of these findings will be discussed in turn, with specific emphasis on theoretical and practical implications.

\section{Type of task}

In general, training that utilised the SST appeared to produce a smaller effect size than training that utilised the GNG, suggesting that different mechanisms may underlie the two tasks, resulting in different effects on behaviour. Verbruggen and Logan (2008) suggest that there are two different types of response inhibition; automatic or 'bottom-up' response inhibition, and controlled or 'top-down' response inhibition. Automatic response inhibition is formed when associations between stimuli and a no-go response are consistent, resulting in bottom-up retrieval of these associations. When these associations are inconsistent, top-down activation of the stop process is required. Preliminary evidence suggests that GNG training is influencing behaviour via bottom up response inhibition. Recently, Houben and Jansen (2015) demonstrated that associations between chocolate stimuli and a 'go' response were significantly reduced in participants who received GNG training compared to control participants. Allom and Mullan (2015) attempted to determine the mechanism underlying SST training suggesting that training improves Stroop performance, arguably a measure requiring controlled response inhibition (Friedman \& Miyake, 2004; MacLeod, 1991). However, while Stroop performance improved in those who received SST training, this did not translate to change in health behaviour. It may be the case that the GNG and SST influence behaviour via 
automatic and controlled response inhibition respectively, but that training automatic response inhibition may be more effective for behaviour change.

Training in which a behaviour-specific GNG, or a behaviour-specific SST, was used produced significant and homogenous effect sizes, whereas neutral-stimuli training did not. This suggests that exercising and strengthening general inhibitory control may not be sufficient to produce changes in behaviour. However, it must be noted that only one included study utilised neutral-stimuli training (Lawrence et al., 2015: Study 3), therefore, conclusions regarding the size and consistency of the effect of neutral training on health behaviour cannot be drawn. Future research should aim to replicate the study by Lawrence et al. (2015) in order to add further evidence to the argument that training needs to include behaviour-specific stimuli in order to achieve behaviour change.

\section{Longevity of effect}

Objective outcomes that were measured immediately after training produced a significant effect, whereas outcomes measured at a later time point did not yield a statistically significant effect, suggesting that training effects do not persist over time. Interestingly, subjective measures, which were all administered at least one day after training, resulted in a small but significant effect. However, this effect may have been inflated due to reporting biases, and the effect size corresponding to laboratory measures that were not immediately administered may be a closer indication of the longevity of the training effect. Indeed, Allom and Mullan (2015) failed to replicate their initial finding that SST training led to weight loss when weight was measured objectively (Study 2) rather than using self-report (Study 1).

\section{Length of training}

Current results indicate no relationship between length of training and effect size; however, it is worth noting that other task parameters such as training paradigm and method of measurement may have masked whether the number of trials influenced the size of the effect. 
Future research should systematically vary the number of trials and sessions in order to determine if more training results in greater benefits to health outcomes.

\section{Behaviour}

Regarding differential training effects according to behaviour type, analyses revealed non-zero effects for both eating behaviour and alcohol consumption. It may be that training is equally effective for behaviours that can be broadly categorised together. In the current example, alcohol and unhealthy food consumption can be categorised as health risk behaviours, both of which require avoiding unhealthy stimuli. Inhibitory control training may be less effective for other categories of behaviour such as behaviours that require approaching healthy stimuli. While inhibitory control has been consistently related to health risk behaviour and less consistently to health promoting behaviour (Allom \& Mullan, 2014), it remains that this assumption needs to be examined experimentally in order for any firm conclusions to be reached.

\section{Limitations}

The inclusion of a relatively small sample of studies may have inflated the overall effect size and therefore caution should be exercised when interpreting some of the reported effects. However, the broad search strategy and inclusion of unpublished works ensured that the overall effect size was not inflated due to statistically significant effects being more likely to be published. The present analysis did not include neurological outcomes such as differences in brain activation as demonstrated by EEG, such as that reported in Bowley et al. (2013). While the primary aim here was to examine the effect of training on behavioural outcomes, such as alcohol consumption and eating behaviour, it may be worthwhile to systematically review the influence of inhibitory control training on neurophysiological outcomes and brain plasticity, particularly to further elucidate the mechanisms by which training may influence behaviour (for a narrative review, see: Spierer et al., 2013). Finally, few studies included a pre-post design to assess change in behaviour; as such, the results of the present meta-analysis primarily 
reflect differences in behaviour between conditions. To address this concern, future research should attempt to include measures that allow for pre- and post-intervention assessment of behavioural outcomes.

\section{Conclusions}

The present meta-analysis provides evidence that inhibitory control training results in statistically significant reductions in health-compromising behaviours such as alcohol consumption and unhealthy eating. The available evidence also suggests that the GNG may be more effective than the SST, these tasks need to be tailored to the target behaviour in order to be successful, and measurement method must be taken into account when evaluating the effects of training. Further research is needed to systematically examine whether length of training influences the size of the effect, and whether the effects of behaviour-specific training persist long after the training session. Determining the optimal length of training, and whether these effects transfer to everyday behaviour, would provide the basis for cost-effective and efficacious methods to reduce health-risk behaviours. 


\section{References}

Allom, V., \& Mullan, B. (2014). Individual differences in executive function predict distinct eating behaviours. Appetite, 80, 123-130. doi: 10.1016/j.appet.2014.05.007

*Allom, V., \& Mullan, B. (2015). Two inhibitory control training interventions designed to improve eating behaviour and determine mechanisms of change. Appetite, 89, 282-290. doi: 10.1016/j.appet.2015.02.022

Borenstein, M., Hedges, L., Higgins, J., \& Rothstein, H. (2005). Comprehensive meta-analysis (Version 2) [Computer Software]. Englewood, NJ: Biostat.

Borenstein, M., Hedges, L., \& Rothstein, H. (2007). Meta-analysis: Fixed effect vs. random effects. Retrieved November, 2013, from http://www.Meta-Analysis.com

*Bowley, C., Faricy, C., Hegarty, B., Johnstone, S., Smith, J., Kelly, P., \& Rushby, J. (2013). The effects of inhibitory control training on alcohol consumption, implicit alcoholrelated cognitions and brain electrical activity. International Journal of Psychophysiology, 89, 342-348. doi: 10.1016/j.ijpsycho.2013.04.011

Cohen, J. (1988). Statistical power analysis for the behavioral sciences (2 ed.). Hillsdale, NJ: Psychology Press.

DerSimonian, R., \& Laird, N. (1986). Meta-analysis in clinical trials. Controlled clinical trials, 7, 177-188. doi: 10.1016/0197-2456(86)90046-2

Donders, F. C. (1969). On the speed of mental processes. Acta Psychologica, 30, 412-431.

Duval, S., \& Tweedie, R. (2000). Trim and Fill: A Simple Funnel Plot-Based Method of Testing and Adjusting for Publication Bias in Meta-Analysis. Biometrics, 56, 455-463. doi: 10.1111/j.0006-341X.2000.00455.x

Egger, M., Smith, G. D., Schneider, M., \& Minder, C. (1997). Bias in meta-analysis detected by a simple, graphical test. British Medical Journal, 315, 629-634. doi: 10.1136/bmj.315.7109.629 
Friedman, N. P., \& Miyake, A. (2004). The relations among inhibition and interference control functions: A latent-variable analysis. Journal of Experimental Psychology: General, 133, 101-135. doi: 10.1037/0096-3445.133.1.101

Gray, J. A., \& McNaughton, N. (2000). The neuropsychology of anxiety: An enquiry into the functions of the septo-hippocampal system: Oxford University Press.

Greenwald, A. G., McGhee, D. E., \& Schwartz, J. L. (1998). Measuring individual differences in implicit cognition: the implicit association test. Journal of Personality and Social Psychology, 74, 1464-1480. doi: 10.1037/0022-3514.74.6.1464

Guerrieri, R., Nederkoorn, C., \& Jansen, A. (2012). Disinhibition is easier learned than inhibition: The effects of (dis) inhibition training on food intake. Appetite, 59, 96-99. doi: 10.1016/j.appet.2012.04.006

Guerrieri, R., Nederkoorn, C., Schrooten, M., Martijn, C., \& Jansen, A. (2009). Inducing impulsivity leads high and low restrained eaters into overeating, whereas current dieters stick to their diet. Appetite, 53, 93-100. doi: doi.org/10.1016/j.appet.2009.05.013

Hall, P. A. (2012). Executive control resources and frequency of fatty food consumption: Findings from an age-stratified community sample. Health Psychology, 31, 235-241. doi: $10.1037 / \mathrm{a} 0025407$

Hallett, J., Maycock, B., Kypri, K., Howat, P., \& McManus, A. (2009). Development of a Web-based alcohol intervention for university students: Processes and challenges. Drug and alcohol review, 28, 31-39. doi: 10.1111/j.1465-3362.2008.00008.x.

Higgins, J. P. T., Thompson, S. G., Deeks, J. J., \& Altman, D. G. (2003). Measuring inconsistency in meta-analyses. BMJ: British Medical Journal, 327, 557-560. doi: doi.org/10.1136/bmj.327.7414.557

Hofmann, W., Friese, M., \& Roefs, A. (2009). Three ways to resist temptation: The independent contributions of executive attention, inhibitory control, and affect 
regulation to the impulse control of eating behavior. Journal of Experimental Social Psychology, 45, 431-435. doi: 10.1016/j.jesp.2008.09.013

Hopewell, S., McDonald, S., Clarke, M., \& Egger, M. (2007). Grey literature in meta-analyses of randomized trials of health care interventions. Cochrane Database of Systematic Reviews, 2. doi:10.1002/14651858.MR000010.pub3

*Houben, K. (2011). Overcoming the urge to splurge: Influencing eating behavior by manipulating inhibitory control. Journal of behavior therapy and experimental psychiatry, 42, 384-388. doi: 10.1016/j.jbtep.2011.02.008

*Houben, K., Havermans, R. C., Nederkoorn, C., \& Jansen, A. (2012). Beer à No-Go: Learning to stop responding to alcohol cues reduces alcohol intake via reduced affective associations rather than increased response inhibition. Addiction, 107, 12801287. doi: 10.1111/j.1360-0443.2012.03827.x

*Houben, K., \& Jansen, A. (2011). Training inhibitory control: A recipe for resisting sweet temptations. Appetite, 56, 345-349. doi: 10.1016/j.appet.2010.12.017

*Houben, K., \& Jansen, A. (2015). Chocolate equals stop: chocolate-specific inhibition training reduces chocolate intake and go associations with chocolate. Appetite, 87, 318323. doi: 10.1016/j.appet.2015.01.005

*Houben, K., Nederkoorn, C., Wiers, R. W., \& Jansen, A. (2011). Resisting temptation: Decreasing alcohol-related affect and drinking behavior by training response inhibition. Drug and alcohol dependence, 116, 132-136. doi: 10.1016/j.drugalcdep.2010.12.011

Houben, K., \& Wiers, R. W. (2009). Response inhibition moderates the relationship between implicit associations and drinking behavior. Alcoholism: Clinical and Experimental Research, 33, 626-633. doi: 10.1111/j.1530-0277.2008.00877.x

Huedo-Medina, T. B., Sánchez-Meca, J., Marin-Martinez, F., \& Botella, J. (2006). Assessing heterogeneity in meta-analysis: Q statistic or $\mathrm{I}^{2}$ index? Psychological methods, 11, 193206. doi: 10.1037/1082-989X.11.2.193 
Hunter, J. E., \& Schmidt, F. L. (2000). Fixed Effects vs. Random Effects Meta-Analysis Models: Implications for Cumulative Research Knowledge. International Journal of Selection and Assessment, 8, 275-292. doi: 10.1111/1468-2389.00156

*Jones, A., \& Field, M. (2013). The effects of cue-specific inhibition training on alcohol consumption in heavy social drinkers. Experimental and Clinical Psychopharmacology, 21, 8-16. doi: 10.1037/a0030683

Lappin, J. S., \& Eriksen, C. W. (1966). Use of a delayed signal to stop a visual reaction-time response. Journal of Experimental Psychology, 72, 805-811. doi: 10.1037/h0021266

*Lawrence, N. S., Verbruggen, F., Morrison, S., Adams, R. C., \& Chambers, C. D. (2015). Stopping to food can reduce intake. Effects of stimulus-specificity and individual differences in dietary restraint. Appetite, 85, 91-103. doi: 10.1016/j.appet.2014.11.006

MacLeod, C. M. (1991). Half a century of research on the Stroop effect: an integrative review. Psychological bulletin, 109, 163-203. doi: 10.1037/0033-2909.109.2.163

Marczinski, C. A., \& Fillmore, M. T. (2003). Preresponse cues reduce the impairing effects of alcohol on the execution and suppression of responses. Experimental and Clinical Psychopharmacology, 11, 110-117. doi: 10.1037/1064-1297.11.1.110

McEachan, R. R. C., Lawton, R. J., \& Conner, M. (2010). Classifying health-related behaviours: Exploring similarities and differences amongst behaviours. British Journal of Health Psychology, 15, 347-366. doi: 10.1348/135910709X466487

Miyake, A., Friedman, N. P., Emerson, M. J., Witzki, A. H., Howerter, A., \& Wager, T. D. (2000). The unity and diversity of executive functions and their contributions to complex "frontal lobe" tasks: A latent variable analysis. Cognitive psychology, 41, 49100. doi: 10.1006/cogp.1999.0734

Muraven, M. (2010). Practicing self-control lowers the risk of smoking lapse. Psychology of Addictive Behaviors, 24, 446-452. doi: 10.1037/a0018545 
Murphy, P., \& Garavan, H. (2011). Cognitive predictors of problem drinking and AUDIT scores among college students. Drug and alcohol dependence, 115, 94-100. doi: 10.1016/j.drugalcdep.2010.10.011

*Nagy, A. B. (2012). “Can you resist temptation?” The effectiveness of computerized response inhibition training to reduce alcohol use among heavy drinkers. (Masters thesis, Maastricht University Maastricht, the Netherlands). Retrieved from http://arno.unimaas.nl/show.cgi?fid=26092

Nederkoorn, C., Houben, K., Hofmann, W., Roefs, A., \& Jansen, A. (2010). Control yourself or just eat what you like? Weight gain over a year is predicted by an interactive effect of response inhibition and implicit preference for snack foods. Health Psychology, 29, 389-393. doi: 10.1037/a0019921

Nigg, J. T. (2000). On inhibition/disinhibition in developmental psychopathology: Views from cognitive and personality psychology and a working inhibition taxonomy. Psychological bulletin, 126, 220-246. doi: 10.1037/0033-2909.126.2.220

Oaten, M., \& Cheng, K. (2006). Longitudinal gains in self-regulation from regular physical exercise. British Journal of Health Psychology, 11, 717-733. doi: $10.1348 / 135910706 \times 96481$

Rosenberg, M. S. (2005). The file-drawer problem revisited: A general weighted method for calculating fail-safe numbers in meta-analysis. Evolution, 59, 464-468. doi; 10.1111/j.0014-3820.2005.tb01004.x

Schachar, R., \& Logan, G. D. (1990). Impulsivity and inhibitory control in normal development and childhood psychopathology. Developmental Psychology, 26, 710. doi: $10.1037 / 0012-1649.26 .5 .710$

Smyth, J., Wonderlich, S., Crosby, R., Miltenberger, R., Mitchell, J., \& Rorty, M. (2001). The use of ecological momentary assessment approaches in eating disorder research. International Journal of Eating Disorders, 30, 83-95. doi: 10.1002/eat.1057 
Sobell, L. C., \& Sobell, M. B. (1992). Timeline follow-back. A technique for assessing selfreported alcohol consumption. In R. Litten \& J. Allen (Eds.), Measuring alcohol consumption (pp. 41-72): Humana Press.

Spierer, L., Chavan, C. F., \& Manuel, A. L. (2013). Training-induced behavioral and brain plasticity in inhibitory control. Frontiers in human neuroscience, 7, 427. doi: 10.3389/fnhum.2013.00427

Sterne, J. A., Egger, M., \& Smith, G. D. (2001). Investigating and dealing with publication and other biases. Systematic Reviews in Health Care: Meta-Analysis in Context, Second Edition 189-208. doi: 10.1002/9780470693926.ch11

Todd, J., \& Mullan, B. (2013). The role of self-monitoring and response inhibition in improving sleep behaviours. International journal of behavioral medicine, 20, 1-8. doi: $10.1007 / \mathrm{s} 12529-013-9328-8$

*van Koningsbruggen, G. M., Veling, H., Stroebe, W., \& Aarts, H. (2013). Comparing two psychological interventions in reducing impulsive processes of eating behaviour: Effects on self-selected portion size. British Journal of Health Psychology. doi: 10.1111/bjhp.12075

*Veling, H., Aarts, H., \& Papies, E. K. (2011). Using stop signals to inhibit chronic dieters' responses toward palatable foods. Behaviour research and therapy, 49, 771-780. doi: 10.1016/j.brat.2011.08.005

Veling, H., Aarts, H., \& Stroebe, W. (2013a). Stop signals decrease choices for palatable foods through decreased food evaluation. Frontiers in psychology, 4, 875. doi: 10.3389/fpsyg.2013.00875

*Veling, H., Aarts, H., \& Stroebe, W. (2013b). Using stop signals to reduce impulsive choices for palatable unhealthy foods. British Journal of Health Psychology, 18, 354-368. doi: 10.1111/j.2044-8287.2012.02092.x 
*Veling, H., van Koningsbruggen, G. M., Aarts, H., \& Stroebe, W. (2014). Targeting impulsive processes of eating behavior via the internet. Effects on body weight. Appetite, 78, 102-109. doi: 10.1016/j.appet.2014.03.014

Verbruggen, F., \& Logan, G. D. (2008). Automatic and controlled response inhibition: Associative learning in the go/no-go and stop-signal paradigms. Journal of Experimental Psychology: General, 137, 649-672. doi: 10.1037/a0013170

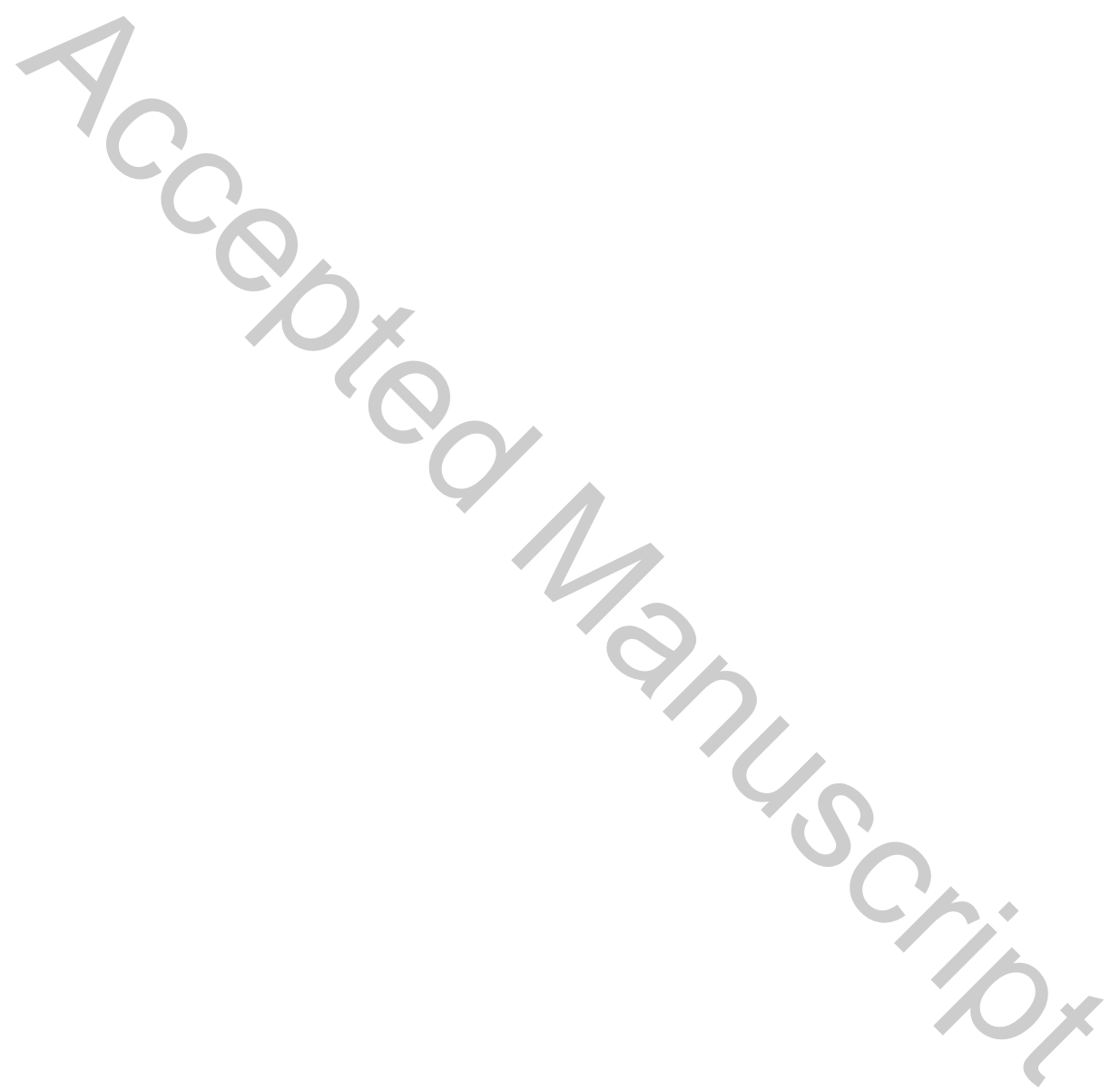


Table 1

Moderator Analysis of the Size of the Effect of Inhibitory Control Training on Health Behaviour

\begin{tabular}{|c|c|c|c|c|c|c|c|c|c|}
\hline \multirow[b]{2}{*}{ Moderator } & \multirow[b]{2}{*}{$\mathrm{k}$} & \multirow[b]{2}{*}{$\mathrm{N}$} & \multicolumn{4}{|c|}{$d$} & \multicolumn{3}{|c|}{ Heterogeneity } \\
\hline & & & $d$ & LL & UL & SE & $Q$ & $I^{2}$ & $\mathrm{Tau}^{2}$ \\
\hline \multicolumn{10}{|l|}{ Training paradigm } \\
\hline GNG & 12 & 771 & .503 & .348 & .658 & .079 & 5.865 & .000 & .000 \\
\hline SST & 7 & 623 & .190 & .000 & .380 & .097 & 4.396 & .000 & .000 \\
\hline \multicolumn{10}{|l|}{ Type of stimuli } \\
\hline Behaviour-specific & 18 & 1248 & .419 & .293 & .546 & .064 & 0.00 & .000 & .000 \\
\hline Neutral & 1 & 146 & -.027 & -.421 & .367 & .201 & 12.038 & .000 & .000 \\
\hline \multicolumn{10}{|l|}{ Type of task } \\
\hline GNG_Specific & 12 & 771 & .503 & .348 & .658 & .079 & 5.865 & .000 & .000 \\
\hline SST_Specific & & 477 & .256 & .039 & .476 & .111 & 2.880 & .000 & .000 \\
\hline SST_Neutral & 1 & 146 & -.027 & -.421 & .367 & .201 & .000 & .000 & .000 \\
\hline \multicolumn{10}{|l|}{ Type of behaviour } \\
\hline Alcohol & 5 & 303 & .433 & .195 & .671 & .121 & .976 & .000 & .000 \\
\hline Eating & 14 & 1091 & .366 & .214 & .518 & .077 & 15.249 & 14.747 & .111 \\
\hline \multicolumn{10}{|l|}{ Objective vs. subjective } \\
\hline Objective & 11 & 1104 & .430 & & & .085 & 11.479 & 12.886 & .101 \\
\hline Subjective & 5 & 290 & .271 & & .506 & .120 & 3.181 & .000 & .000 \\
\hline \multicolumn{10}{|l|}{ Length of follow up } \\
\hline Immediate & 9 & 919 & .433 & .261 & .605 & & 8.367 & 4.389 & .055 \\
\hline Post & 7 & 475 & .295 & .085 & .506 & .107 & 6.424 & 6.604 & .074 \\
\hline \multicolumn{10}{|l|}{ Measurement } \\
\hline Objective_Immediate & 9 & 919 & .433 & .261 & .605 & .088 & & 4.389 & .055 \\
\hline Objective_Post & 2 & 185 & .404 & -.294 & 1.102 & .356 & 3.050 & 67.210 & .413 \\
\hline Subjective_Post & 5 & 290 & .271 & .036 & .506 & .120 & 3.181 & .000 & .000 \\
\hline
\end{tabular}

Note. GNG_Specific = behaviour-specific go/no-go task; SST_Specific $=$ behaviour specific stop-signal task; SST_Neutral = neutral stop-signal task; Objective_Immediate $=$ objective outcome measure administered immediately after training session; Objective_Post = objective outcome measure administered at least 1 day after training session, Subjective_Post $=$ subjective measure administered at least one day after training 


\section{Figure Captions}

Figure 1. Flow diagram for the search and inclusion criteria for studies in the meta-analysis.

Figure 2. Forest plot of included effects.

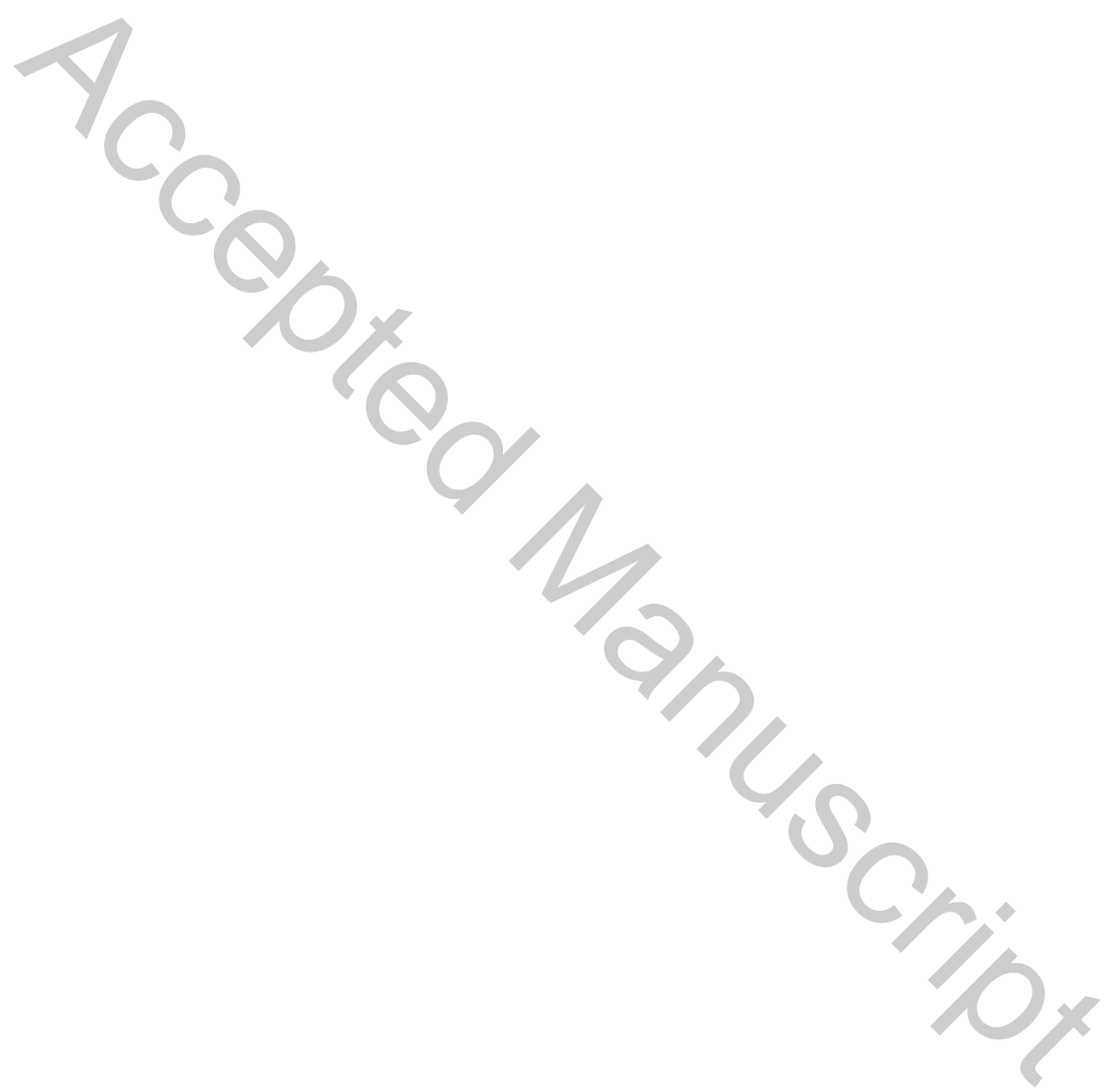



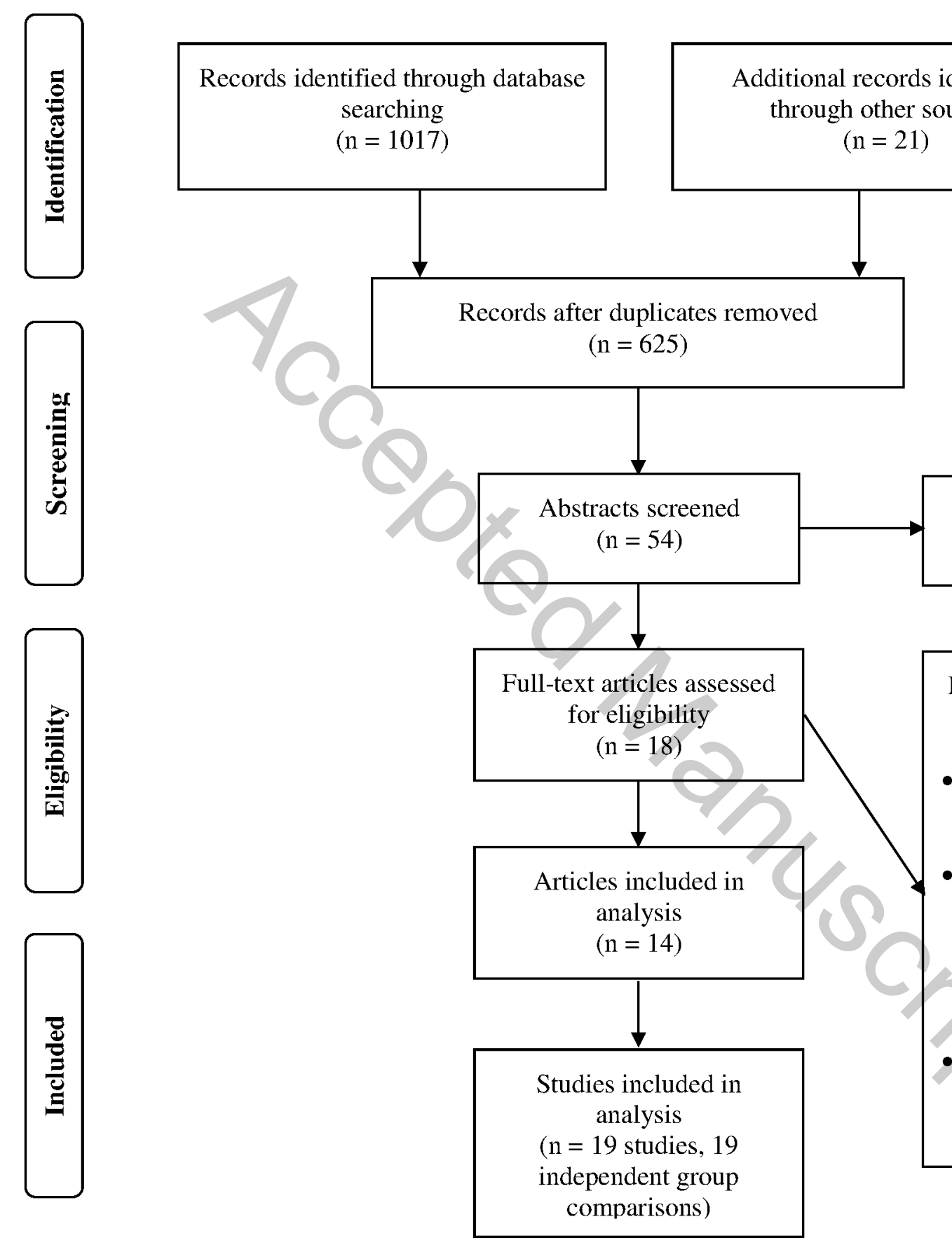

Full-text articles excluded, with reasons $(n=4)$

- Used unsuitable behavioural measures $(\mathrm{n}=1$; Veling, Aarts, \& Stroebe, 2013a)

- Could not obtain data from manuscript or authors $(\mathrm{n}=$ 2; Guerrieri, Nederkoorn, \& Jansen, 2012; Guerrieri, Nederkoorn, Schrooten, Martijn, \& Jansen, 2009)

- Used multiple intervention techniques $(\mathrm{n}=1$; Todd \& Mullan, 2013) 


\begin{tabular}{|c|c|c|c|c|c|c|c|c|c|}
\hline Study & $d$ & LL & $\mathrm{UL}$ & $p$ & -1.000 & -0.500 & 0.000 & 0.500 & 1.000 \\
\hline Allom and Mullan (2015; Study 1) & 0.015 & -0.519 & 0.550 & 0.955 & & & & & \\
\hline Allom and Mullan (2015; Study 2) & 0.014 & -0.544 & 0.572 & 0.961 & & & & & \\
\hline Bowley et al. (2013) & 0.324 & -0.308 & 0.956 & 0.315 & & & & & \\
\hline Houben (2011) & 0.446 & -0.075 & 0.967 & 0.093 & & & & & \\
\hline Houben et al. (2012) & 0.509 & 0.118 & 0.900 & 0.011 & & & & & \\
\hline Houben and Jansen (2011) & 0.540 & -0.083 & 1.163 & 0.090 & & & & & \\
\hline Houben and Jansen (2015) & 0.598 & 0.042 & 1.153 & 0.035 & & & & & \\
\hline Houben, Nederkoorn et al. (2011) & 0.585 & 0.033 & 1.138 & 0.038 & & & & & \\
\hline Jones and Field (2012; Study 1) & 0.263 & -0.270 & 0.796 & 0.334 & & & & & \\
\hline Lawrence et al. (2014; Study 1) & 0.562 & 0.016 & 1.107 & 0.043 & & & & & \\
\hline Lawrence et al. (2014; Study 2) & 0.319 & -0.097 & 0.735 & 0.133 & & & & & \\
\hline Lawrence et al. (2014; Study 3) & -0.027 & -0.421 & 0.367 & 0.894 & & & & & \\
\hline Nagy $(2012)$ & 0.365 & -0.368 & 1.098 & 0.329 & & & & & \\
\hline van Koningsbruggen et al. (2013; Study 1) & 0.775 & 0.175 & 1.375 & 0.011 & & & & & \\
\hline van Koningsbruggen et al. (2013; Study 2) & 0.761 & 0.162 & 1.360 & 0.013 & & & & & \\
\hline Veling, Aarts, and Papies (2011; Study 2) & 0.265 & -0.316 & 0.846 & 0.371 & & & & & \\
\hline Veling, Aarts, and Stroebe (2013; Study 1) & 0.716 & 0.106 & 1.326 & 0.022 & & & & & \\
\hline Veling, Aarts, and Stroebe (2013; Study 2) & 0.539 & 0.089 & 0.988 & 0.019 & & & & & \\
\hline Veling et al. (2014) & 0.062 & -0.468 & 0.592 & 0.819 & & & & & \\
\hline Total effect & 0.378 & 0.258 & 0.498 & 0.000 & & & & & \\
\hline
\end{tabular}




\section{Supplementary Materials}

Does Inhibitory Control Training Improve Health Behaviour? A Meta-Analysis

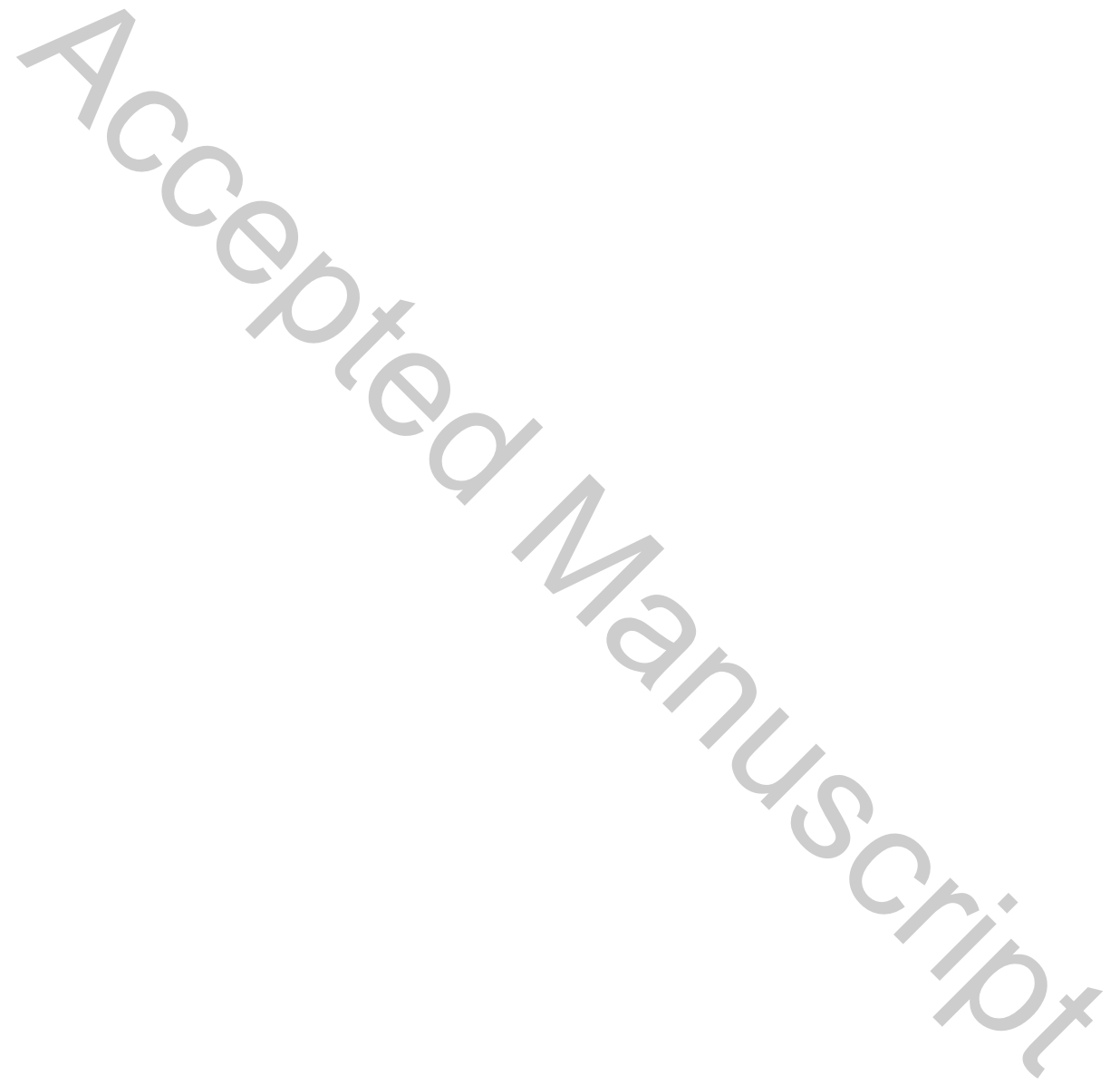




\section{References included in the meta-analysis}

Allom, V., \& Mullan, B. (2015). Two inhibitory control training interventions designed to improve eating behaviour and determine mechanisms of change. Appetite. doi: doi:10.1016/j.appet.2015.02.022

Bowley, C., Faricy, C., Hegarty, B., Johnstone, S., Smith, J., Kelly, P., \& Rushby, J. (2013). The effects of inhibitory control training on alcohol consumption, implicit alcoholrelated cognitions and brain electrical activity. International Journal of Psychophysiology, 89, 342-348. doi: 10.1016/j.ijpsycho.2013.04.011

Houben, K. (2011). Overcoming the urge to splurge: Influencing eating behavior by manipulating inhibitory control. Journal of behavior therapy and experimental psychiatry, 42, 384-388. doi: 10.1016/j.jbtep.2011.02.008

Houben, K., Havermans, R. C., Nederkoorn, C., \& Jansen, A. (2012). Beer à No-Go: Learning to stop responding to alcohol cues reduces alcohol intake via reduced affective associations rather than increased response inhibition. Addiction, 107, 12801287. doi: 10.1111/j.1360-0443.2012.03827.x

Houben, K., \& Jansen, A. (2011). Training inhibitory control: A recipe for resisting sweet temptations. Appetite, 56, 345-349. doi: 10.1016/j.appet.2010.12.017

Houben, K., \& Jansen, A. (2015). Chocolate equals stop: chocolate-specific inhibition training reduces chocolate intake and go associations with chocolate. Appetite, 87 318-323. doi: 10.1016/j.appet.2015.01.005

Houben, K., Nederkoorn, C., Wiers, R. W., \& Jansen, A. (2011). Resisting temptation: Decreasing alcohol-related affect and drinking behavior by training response inhibition. Drug and alcohol dependence, 116, 132-136. doi: 10.1016/j.drugalcdep.2010.12.011 
Jones, A., \& Field, M. (2012). The effects of cue-specific inhibition training on alcohol consumption in heavy social drinkers. Experimental and Clinical Psychopharmacology, 21, 8-16. doi: 10.1037/a0030683

Lawrence, N. S., Verbruggen, F., Morrison, S., Adams, R. C., \& Chambers, C. D. (2015). Stopping to food can reduce intake. Effects of stimulus-specificity and individual differences in dietary restraint. Appetite, 85 91-103. doi: 10.1016/j.appet.2014.11.006

Nagy, A. B. (2012). “Can you resist temptation?” The effectiveness of computerized response inhibition training to reduce alcohol use among heavy drinkers. (Masters thesis, Maastricht University Maastricht, the Netherlands). Retrieved from http://arno.unimaas.nl/show.cgi?fid=26092

van Koningsbruggen, G. M., Veling, H., Stroebe, W., \& Aarts, H. (2013). Comparing two psychological interventions in reducing impulsive processes of eating behaviour: Effects on self-selected portion size. British Journal of Health Psychology. doi: 10.1111/bjhp.12075

Veling, H., Aarts, H., \& Papies, E. K. (2011). Using stop signals to inhibit chronic dieters' responses toward palatable foods. Behaviour research and therapy, 49, 771-780. doi: 10.1016/j.brat.2011.08.005

Veling, H., Aarts, H., \& Stroebe, W. (2013). Using stop signals to reduce impulsive choices for palatable unhealthy foods. British Journal of Health Psychology, 18, 354-368. doi: 10.1111/j.2044-8287.2012.02092.x

Veling, H., van Koningsbruggen, G. M., Aarts, H., \& Stroebe, W. (2014). Targeting impulsive processes of eating behavior via the internet. Effects on body weight. Appetite, 78 102-109. doi: 10.1016/j.appet.2014.03.014 
Table 1

Effect Sizes and Characteristics of Studies Included In the Meta-Analysis

\begin{tabular}{|c|c|c|c|c|c|c|c|c|c|}
\hline Study & Task; stimuli & Behaviour & $\begin{array}{l}\text { Training } \\
\text { condition }\end{array}$ & $\begin{array}{l}\text { Control } \\
\text { condition }\end{array}$ & $\begin{array}{l}\text { Sessions; trials } \\
\text { in each session }\end{array}$ & $\begin{array}{l}\text { Behavioural } \\
\text { outcome }\end{array}$ & $\begin{array}{l}\text { Result (training } \\
\text { versus control) }\end{array}$ & Participants & $d$ \\
\hline $\begin{array}{l}\text { Allom and Mullan } \\
\text { (2015; Study 1) }\end{array}$ & $\begin{array}{l}\text { SST; } \\
\text { behaviour- } \\
\text { specific }\end{array}$ & $\begin{array}{l}\text { Eating } \\
\text { behaviour }\end{array}$ & $\begin{array}{l}\text { Snacks } \\
\text { paired with } \\
\text { stop }\end{array}$ & $\begin{array}{l}\text { No stop- } \\
\text { signal }^{\mathrm{c}}\end{array}$ & $\begin{array}{l}10 \text { across } 10 \\
\text { days; } 192\end{array}$ & $\begin{array}{l}\text { Saturated fat } \\
\text { intake }\end{array}$ & n.s. & $\begin{array}{l}72 \text { undergraduates; } \\
\text { intention to eat } \\
\text { healthily }\end{array}$ & $.02^{\mathrm{a}}$ \\
\hline $\begin{array}{l}\text { Allom and Mullan } \\
\text { (2015; Study 2) }\end{array}$ & $\begin{array}{l}\text { SST; } \\
\text { behaviour- } \\
\text { specific }\end{array}$ & $\begin{array}{l}\text { Eating } \\
\text { behaviour }\end{array}$ & $\begin{array}{l}\text { Snacks } \\
\text { paired with } \\
\text { stop }\end{array}$ & 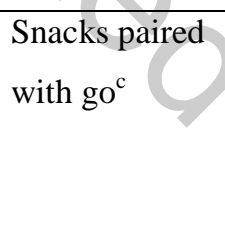 & 10 across 10 & $\begin{array}{l}\text { Percentage fat } \\
\text { intake }\end{array}$ & n.s. & $\begin{array}{l}70 \text { university staff } \\
\text { and students; } \\
\text { intention to eat } \\
\text { healthily }\end{array}$ & $.01^{\mathrm{a}}$ \\
\hline $\begin{array}{l}\text { Bowley et al. } \\
\text { (2013) }\end{array}$ & $\begin{array}{l}\text { GNG; } \\
\text { behaviour- } \\
\text { specific }\end{array}$ & $\begin{array}{l}\text { Alcohol } \\
\text { consumption }\end{array}$ & Beer no-go & Beer go ${ }^{d}$ & $1 ; 80$ & $\begin{array}{l}\text { Beer consumed in } \\
\text { taste test; } \\
\text { Self-report alcohol } \\
\text { consumption }\end{array}$ & $\begin{array}{l}\text { Training condition } \\
\text { consumed less beer; } \\
\text { n.s }\end{array}$ & $\begin{array}{l}59 \text { undergraduates; } \\
\text { drink beer regularly } \\
\text { and have a } \\
\text { preference for beer }\end{array}$ & $.32^{\mathrm{b}}$ \\
\hline Houben (2011) & $\begin{array}{l}\text { GNG; } \\
\text { behaviour- } \\
\text { specific; } \\
\text { within } \\
\text { subjects }\end{array}$ & $\begin{array}{l}\text { Eating } \\
\text { behaviour }\end{array}$ & $\begin{array}{l}\text { Snacks } \\
\text { paired with } \\
\text { stop }\end{array}$ & $\begin{array}{l}\text { Snacks paired } \\
\text { with go }\end{array}$ & $1 ; 288$ & $\begin{array}{l}\text { Snacks consumed } \\
\text { in taste test }\end{array}$ & n.s. & $\begin{array}{l}29 \text { female } \\
\text { undergraduates; } \\
\text { positive } \\
\text { attitudes/liking } \\
\text { towards snacks }\end{array}$ & .45 \\
\hline $\begin{array}{l}\text { Houben et al. } \\
\text { (2012) }\end{array}$ & $\begin{array}{l}\text { GNG; } \\
\text { behaviour- } \\
\text { specific }\end{array}$ & $\begin{array}{l}\text { Alcohol } \\
\text { consumption }\end{array}$ & Beer no-go & Beer go & $1 ; 320$ & $\begin{array}{l}\text { Self- reported } \\
\text { alcohol } \\
\text { consumption }\end{array}$ & $\begin{array}{l}\text { Training condition } \\
\text { reported lower } \\
\text { alcohol consumption }\end{array}$ & $\begin{array}{l}57 \text { heavy drinkers; } \\
\text { have a preference for } \\
\text { beer }\end{array}$ & $.51 *^{\mathrm{a}}$ \\
\hline
\end{tabular}




\begin{tabular}{|c|c|c|c|c|c|c|c|c|c|}
\hline $\begin{array}{l}\text { Houben and Jansen } \\
\text { (2011) }\end{array}$ & $\begin{array}{l}\text { GNG; } \\
\text { behaviour- } \\
\text { specific }\end{array}$ & $\begin{array}{l}\text { Eating } \\
\text { behaviour }\end{array}$ & $\begin{array}{l}\text { Chocolate } \\
\text { no-go }\end{array}$ & Chocolate go ${ }^{\mathrm{c}}$ & $1 ; 320$ & $\begin{array}{l}\text { Chocolate } \\
\text { consumption in } \\
\text { taste test }\end{array}$ & n.s. & $\begin{array}{l}63 \text { female } \\
\text { undergraduates; trait } \\
\text { chocolate cravers }\end{array}$ & .54 \\
\hline $\begin{array}{l}\text { Houben and Jansen } \\
(2015)\end{array}$ & $\begin{array}{l}\text { GNG; } \\
\text { behaviour- } \\
\text { specific }\end{array}$ & $\begin{array}{l}\text { Eating } \\
\text { behaviour }\end{array}$ & $\begin{array}{l}\text { Chocolate } \\
\text { no-go }\end{array}$ & Chocolate go & $1 ; 320$ & $\begin{array}{l}\text { Chocolate } \\
\text { consumption in } \\
\text { taste test }\end{array}$ & $\begin{array}{l}\text { Training condition } \\
\text { consumed less } \\
\text { chocolate }\end{array}$ & $\begin{array}{l}41 \text { female } \\
\text { undergraduates; like } \\
\text { to consume } \\
\text { chocolate regularly }\end{array}$ & $.60 *$ \\
\hline $\begin{array}{l}\text { Houben, } \\
\text { Nederkoorn, et al. } \\
\text { (2011) }\end{array}$ & $\begin{array}{l}\text { GNG; } \\
\text { behaviour- } \\
\text { specific }\end{array}$ & $\begin{array}{l}\text { Alcohol } \\
\text { consumption }\end{array}$ & Beer no-go & Beer go & $1 ; 80$ & $\begin{array}{l}\text { Beer consumed in } \\
\text { taste test; } \\
\text { Self-report alcohol } \\
\text { consumption }\end{array}$ & $\begin{array}{l}\text { Training condition } \\
\text { consumed less beer; } \\
\text { Training condition } \\
\text { reported lower } \\
\text { alcohol consumption }\end{array}$ & $\begin{array}{l}52 \text { heavy drinkers; } \\
\text { have a preference for } \\
\text { beer }\end{array}$ & $.59^{\mathrm{a}, \mathrm{b}}$ \\
\hline $\begin{array}{l}\text { Jones and Field } \\
(2012 ; \text { Study } 1)\end{array}$ & $\begin{array}{l}\text { SST; } \\
\text { behaviour- } \\
\text { specific }\end{array}$ & $\begin{array}{l}\text { Alcohol } \\
\text { consumption }\end{array}$ & $\begin{array}{l}\text { Alcohol } \\
\text { paired with } \\
\text { stop }^{\mathrm{e}}\end{array}$ & $\begin{array}{l}\text { Told to ignore } \\
\text { signal (go) }\end{array}$ & & $\begin{array}{l}\text { Alcohol consumed } \\
\text { in taste test; }\end{array}$ & $\begin{array}{l}\text { Training condition } \\
\text { reported less alcohol } \\
\text { consumption } \\
\text { n.s. }\end{array}$ & $\begin{array}{l}90 \text { university staff } \\
\text { and students; heavy } \\
\text { social drinkers; } \\
\text { liking of beer }\end{array}$ & $.26^{\mathrm{b}}$ \\
\hline $\begin{array}{l}\text { Lawrence et al. } \\
\text { (2015; Study } 1)\end{array}$ & $\begin{array}{l}\text { SST; } \\
\text { behaviour- } \\
\text { specific }\end{array}$ & $\begin{array}{l}\text { Eating } \\
\text { behaviour }\end{array}$ & $\begin{array}{l}\text { Snacks } \\
\text { paired with } \\
\text { stop }\end{array}$ & $\begin{array}{l}\text { Snacks paired } \\
\text { with double- } \\
\text { response }\end{array}$ & $1 ; 480$ & $\begin{array}{l}\text { Snack } \\
\text { consumption }\end{array}$ & $\begin{array}{l}\text { Training condition } \\
\text { consumed fewer } \\
\text { snacks }\end{array}$ & $\begin{array}{l}54 \text { university staff } \\
\text { and students }\end{array}$ & $.56^{*}$ \\
\hline $\begin{array}{l}\text { Lawrence et al. } \\
\text { (2015; Study 2) }\end{array}$ & $\begin{array}{l}\text { SST; } \\
\text { behaviour- } \\
\text { specific; } \\
\text { within } \\
\text { subjects }\end{array}$ & $\begin{array}{l}\text { Eating } \\
\text { behaviour }\end{array}$ & $\begin{array}{l}\text { Snacks } \\
\text { paired with } \\
\text { stop }\end{array}$ & $\begin{array}{l}\text { Snacks paired } \\
\text { with double- } \\
\text { response }\end{array}$ & $1 ; 510$ & $\begin{array}{l}\text { Snack } \\
\text { consumption in } \\
\text { taste test }\end{array}$ & & $\begin{array}{l}136 \text { university staff } \\
\text { and students }\end{array}$ & .32 \\
\hline
\end{tabular}




\begin{tabular}{|c|c|c|c|c|c|c|c|c|c|}
\hline $\begin{array}{l}\text { Lawrence et al. } \\
\text { (2015; Study } 3 \text { ) }\end{array}$ & SST; neutral & $\begin{array}{l}\text { Eating } \\
\text { behaviour }\end{array}$ & $\begin{array}{l}\text { Neutral } \\
\text { paired with } \\
\text { stop }\end{array}$ & $\begin{array}{l}\text { Neutral paired } \\
\text { with double- } \\
\text { response }\end{array}$ & $1 ; 510$ & $\begin{array}{l}\text { Snack } \\
\text { consumption in } \\
\text { taste test }\end{array}$ & n.s. & $\begin{array}{l}146 \text { university staff } \\
\text { and students }\end{array}$ & -.03 \\
\hline Nagy (2012) & $\begin{array}{l}\text { SST; } \\
\text { behaviour- } \\
\text { specific }\end{array}$ & $\begin{array}{l}\text { Alcohol } \\
\text { consumption }\end{array}$ & $\begin{array}{l}\text { Alcohol } \\
\text { paired with } \\
\text { stop }^{\text {e }}\end{array}$ & No stop-signal & $\begin{array}{l}5 \text { across } 5 \text { days; } \\
192\end{array}$ & $\begin{array}{l}\text { Alcohol consumed } \\
\text { in taste test; } \\
\text { Self-report alcohol } \\
\text { consumption }\end{array}$ & $\begin{array}{l}\text { n.s. } \\
\text { n.s. }\end{array}$ & 45 heavy drinkers & $\begin{array}{l}\mathrm{n} / \mathrm{a} \\
.37^{\mathrm{a}}\end{array}$ \\
\hline $\begin{array}{l}\text { van } \\
\text { Koningsbruggen et } \\
\text { al. (2013; Study } 1)\end{array}$ & $\begin{array}{l}\text { GNG; } \\
\text { behaviour- } \\
\text { specific }\end{array}$ & $\begin{array}{l}\text { Eating } \\
\text { behaviour }\end{array}$ & $\begin{array}{l}\text { Sweets no- } \\
\text { go }\end{array}$ & Sweets go $^{\mathrm{g}}$ & $1 ; 72$ & $\begin{array}{l}\text { Sweets selected } \\
\text { in food serving } \\
\text { task }\end{array}$ & $\begin{array}{l}\text { Training condition } \\
\text { selected fewer } \\
\text { sweets }\end{array}$ & 89 undergraduates & $.78^{*}$ \\
\hline $\begin{array}{l}\text { van } \\
\text { Koningsbruggen et } \\
\text { al. (2013; Study 2) }\end{array}$ & $\begin{array}{l}\text { GNG; } \\
\text { behaviour- } \\
\text { specific }\end{array}$ & $\begin{array}{l}\text { Eating } \\
\text { behaviour }\end{array}$ & $\begin{array}{l}\text { Sweets no- } \\
\text { go }\end{array}$ & Sweets $\mathrm{go}^{\mathrm{g}}$ & $1 ; 72$ & $\begin{array}{l}\text { Snacks dispensed } \\
\text { in a virtual snack } \\
\text { dispenser }\end{array}$ & $\begin{array}{l}\text { Training condition } \\
\text { dispensed fewer } \\
\text { snacks }\end{array}$ & 88 undergraduates & $.76^{*}$ \\
\hline $\begin{array}{l}\text { Veling, Aarts, and } \\
\text { Papies (2011; } \\
\text { Study 2) }\end{array}$ & $\begin{array}{l}\text { GNG; } \\
\text { behaviour- } \\
\text { specific }\end{array}$ & $\begin{array}{l}\text { Eating } \\
\text { behaviour }\end{array}$ & $\begin{array}{l}\text { Sweets no- } \\
\text { go }\end{array}$ & Sweets go & 1.77 & $\begin{array}{l}\text { Sweets } \\
\text { consumption } \\
\text { (take home bag) }\end{array}$ & n.s. & 46 undergraduates & .27 \\
\hline $\begin{array}{l}\text { Veling, Aarts, and } \\
\text { Stroebe (2013; } \\
\text { Study 1) }\end{array}$ & $\begin{array}{l}\text { GNG; } \\
\text { behaviour- } \\
\text { specific }\end{array}$ & $\begin{array}{l}\text { Eating } \\
\text { behaviour }\end{array}$ & $\begin{array}{l}\text { Snacks no- } \\
\text { go }\end{array}$ & Snacks go & $1 ; 96$ & $\begin{array}{l}\text { Unhealthy } \\
\text { choices }\end{array}$ & $\begin{array}{l}\text { Training condition } \\
\text { made fewer } \\
\text { unhealthy choices }\end{array}$ & $\begin{array}{l}79 \text { adults/community } \\
\text { sample }\end{array}$ & $.72 *$ \\
\hline $\begin{array}{l}\text { Veling Aarts, and } \\
\text { Stroebe (2013; } \\
\text { Study 2) }\end{array}$ & $\begin{array}{l}\text { GNG; } \\
\text { behaviour- } \\
\text { specific }\end{array}$ & $\begin{array}{l}\text { Eating } \\
\text { behaviour }\end{array}$ & $\begin{array}{l}\text { Snacks no- } \\
\text { go }\end{array}$ & Snacks go & $1 ; 96$ & $\begin{array}{l}\text { Unhealthy } \\
\text { choices under } \\
\text { cognitive load }\end{array}$ & $\begin{array}{l}\text { Training condition } \\
\text { made fewer } \\
\text { unhealthy choices }\end{array}$ & $\begin{array}{l}44 \text { adults/ } \\
\text { community sample }\end{array}$ & $.54^{*}$ \\
\hline
\end{tabular}




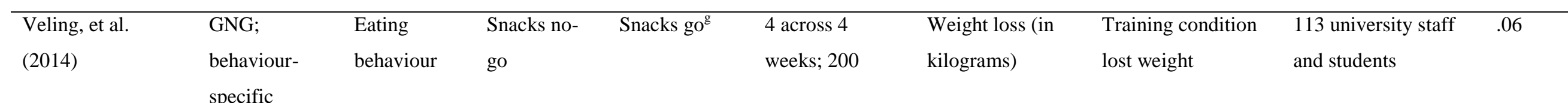

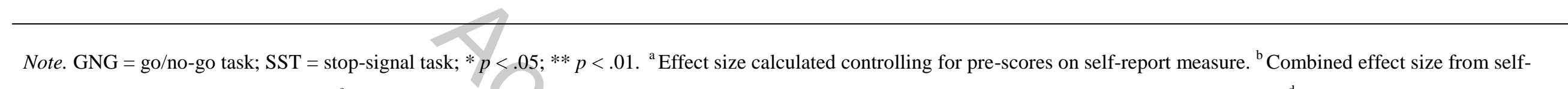

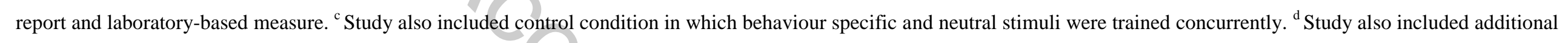
control condition: Brief Alcohol Intervention. ${ }^{\mathrm{e}}$ Study also included inhibitory control training condition with neutral stimuli. ${ }^{\mathrm{f}}$ Study also included a no-response, ignore signal

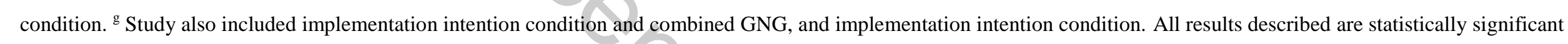
unless otherwise specified. n.s. $=$ not statistically significant at .05 level. 